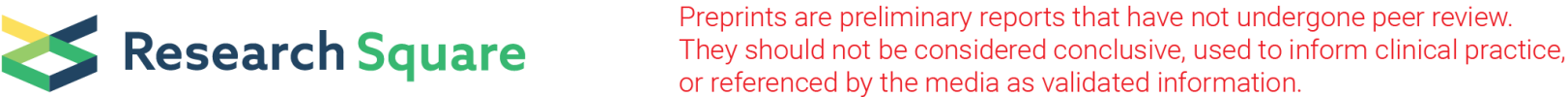

\section{Atypical Ductal Hyperplasia of the Breast on Core Needle Biopsy - Risk of Malignant Upgrade on Surgical Excision.}

Tiffany Sin Hui Bong ( $\square$ tiffany.bong@mohh.com.sg )

Singapore General Hospital https://orcid.org/0000-0002-9376-6640

Thaddaeus Tan

Singapore General Hospital

Juliana TS Ho

Singapore General Hospital

Puay Hoon Tan

Singapore General Hospital

Wing Sze Lau

Singapore General Hospital

Tuan Meng Tan

National University Singapore - Kent Ridge Campus: National University of Singapore

Jill SL Wong

Singapore General Hospital

Veronique KM Tan

Singapore General Hospital

\section{Benita KT Tan}

Singapore General Hospital

Preetha Madhukumar

Singapore General Hospital

\section{Wei Sean Yong}

Singapore General Hospital

Sue Zann Lim

Singapore General Hospital

Ong Kong Wee

Singapore General Hospital

Chow Yin Wong

Singapore General Hospital

Yirong Sim

National Cancer Centre Singapore https://orcid.org/0000-0001-8758-0455 


\section{Research Article}

Keywords: atypical ductal hyperplasia, core needle biopsy, malignant upgrade, excision biopsy, normogram

Posted Date: May 21st, 2021

DOl: https://doi.org/10.21203/rs.3.rs-523022/v1

License: (c) (i) This work is licensed under a Creative Commons Attribution 4.0 International License. Read Full License

Version of Record: A version of this preprint was published at Journal of Breast Cancer on January 1st, 2022. See the published version at https://doi.org/10.4048/jbc.2022.25.e7. 


\section{Abstract}

Purpose: Atypical ductal hyperplasia $(A D H)$ is a high risk lesion with an increased risk of developing breast cancer. This study aims to identify factors predictive of malignant upgrade for ADH diagnosed on core needle biopsy (CNB) and to develop a nomogram to facilitate evidence-based decision making.

Methods: Retrospective analysis of women with CNB diagnosed ADH at the National Cancer Centre Singapore between 2010 and 2015 was performed. Cox proportional hazards regression was used to identify independent clinical, radiological and histological factors associated with malignant upgrade. A nomogram was constructed and multivariable logistic regression coefficients were used to estimate the predicted probability of upgrade for each factor combination. Combinations with the lowest predicted probabilities $(\leq 5 \%)$ were identified as low risk. Model sensitivity, specificity, positive and negative predictive values were assessed.

Results: From 2010-2015, 238,122 women underwent screening under the national breast cancer screening programme. 29,564 women were recalled and 5742 CNBs were performed, of which 2686 were performed at NCCS. 88 patients (90 lesions) were diagnosed with ADH. 26 lesions were upgraded to a breast malignancy on excision biopsy. On univariate analysis, presence of a mass on either ultrasound $(p=0.018)$ or mammogram $(p=0.026)$, presence of mammographic microcalcifications $(p=0.047)$, diffuse microcalcification distribution ( $p=0.034)$, mammographic parenchymal density $(p=0.008)$, presence of microcalcifications on biopsy $(p=0.037)$ and three or more separate foci of ADH found on biopsy $(p=0.024)$ were associated with malignant upgrade. Mammographic parenchymal density (Hazard ratio= $0.04,95 \% \mathrm{Cl} 0.005-0.35, \mathrm{p}=0.014$ ), presence of a mass on ultrasound (Hazard ratio $=10.50,95 \% \mathrm{Cl} 9.21$ $25.2, \mathrm{p}=0.010$ ) and number of foci of $\mathrm{ADH}$ (Hazard ratio $=1.877,95 \% \mathrm{Cl} 1.831-1.920, \mathrm{p}=0.002$ ) remained significant on multivariate analysis and were included in the normogram which demonstrated good discrimination with C-statistic of 0.81 [95\% $\mathrm{Cl}, 0.74$ to 0.88 ].

Conclusion: Our model provides good discrimination of breast cancer risk prediction in patients with ADH on CNB. A subset of women at low risk $(<5 \%)$ of upgrade to cancer may avoid surgical excision following a core-needle biopsy diagnosis of $\mathrm{ADH}$.

\section{Introduction}

Percutaneous core needle biopsy (CNB) is widely performed for diagnosis of radiologically suspicious breast lesions. Found in up to $15 \%$ of CNB specimens [1 2], atypical ductal hyperplasia (ADH) of the breast is considered a high risk lesion that is biologically related to low nuclear grade ductal carcinoma in situ (DCIS). It is associated with an increased risk of developing breast cancer, with a relative risk of 4 , and a cumulative incidence of breast cancer approaching $30 \%$ at 25 years of follow-up [3]. ADH may also coexist with DCIS or invasive breast cancer. This risk is further augmented up to ten times in patients with a family history of breast cancer [4-8] . 
The distinction between low nuclear grade DCIS and ADH can be challenging and inter-observer variation between pathologists is frequent. Often regarded as a borderline epithelial lesion [9-11], the pathological diagnosis of $\mathrm{ADH}$ has been refined with histological criteria of cytoarchitectural atypia affecting less than two separate duct spaces [12] or with a size or extent of no more than $2 \mathrm{~mm}$ in maximum dimension [13]. However, because of the possibility of sampling error with CNBs, the risk of size underestimation, as well as missing a co-existing breast malignancy, an excision biopsy after the diagnosis of ADH on CNB is still recommended [14].

The risk of upgrading of $A D H$ on CNB to an in-situ carcinoma or invasive carcinoma ranges from 19 to $87 \%[1,2,15-20]$. However, in many instances, no upgrade lesion is identified. Therefore strategies that may reliably identify $A D H$ patients at low risk of upgrade are of great interest to allow for the selection of women who can be safely observed. Several groups including Nguyen et al. [21] from MD Anderson Cancer Centre and Pena et al. [22] from Mayo Clinic have attempted to triage patients with ADH lesions found on core biopsy according to the risk of upgrade to an associated carcinoma. However the study population in these reports are Caucasians. Asian women have smaller breasts with denser breast parenchyma and may have different features which portend malignancy. Our national screening program, BreastScreen Singapore (BSS), initiated in 2002, now has 18 years of records. We aim to examine the upgrade rate of $\mathrm{ADH}$ on excision biopsy within BSS, evaluate the clinical, radiological and histological factors that may predict upgrading to DCIS or invasive cancer and to develop a nomogram to strengthen risk benefit-based decision-making.

\section{Methods}

The study was carried out with the approval of the SingHealth Centralized Institutional Review Board. Retrospective analysis of a prospectively maintained database of the national breast cancer screening program, BreastScreen Singapore (BSS), was performed. Consecutive patients who were recalled for imaging abnormalities and had ADH diagnosed on CNB in the National Cancer Centre Singapore, one of the assessment centres, between 2010 and 2015 were included. All mammograms were read by at least two specialist breast radiologists. All core biopsies were performed with either 11- or 14-gauge Trucut or vacuum-assisted breast biopsy (VABB). All patients with ADH diagnosed on Trucut or VABB were identified and included. Histologic upgrading is defined as a lesion diagnosed as ADH on CNB that subsequently revealed malignancy (DCIS and/or invasive carcinoma) on follow up surgical excision. The associations between clinical, radiological and histological factors were assessed via Fisher's exact test. To identify independent clinico radio- orhistological factors associated with an upgrade to malignancy, multivariate analysis using Cox regression model was used. In developing a multivariate model, we followed the recommendation of $\geq 10$ events per variable to avoid overfitting and to optimize generalizability to other settings [23]. The multivariable logistic regression coefficients were used to estimate the predicted probability of upgrade for each factor combination, and those combinations with the lowest predicted probabilities $(\leq 5 \%)$ were identified as low risk of upgrade. All tests were two-sided, and $p$ values of $<0.05$ were considered statistically significant. Analyses were conducted using SPSS version 14.0 (SPSS Inc, Chicago, USA). 
In creating a multivariate model to identify a group with a low risk of upgrade, several potentially important variables were identified. A simple model including the three variables with the strongest association in multivariate analysis was chosen.

Secondary approaches to model choice, including stepwise variable selection and also a model including all univariately significant variables, were explored. However these models were rejected due to concerns regarding multicollinearity of predictor variables, overfitting, and increased complexity for clinical use without substantial improvement in performance. Therefore, we opted for the original three-variable model as our final model (Fig. 1).

\section{Results}

\section{(I) Demographics}

From 1st January 2010 to 31st December 2015, 238,122 women underwent mammographic screening under BSS. 5742 breast core needle biopsies were performed for suspicious lesions detected through this radiographic imaging. 2686 of these core needle biopsies were performed at the BSS clinic at National Cancer Centre Singapore. Of these, 88 patients with 90 ADH lesions were diagnosed through core needle biopsy, 2 patients had bilateral ADH. 71 lesions were biopsied by VABB, 10 by Trucut and 9 by both Trucut and VABB. In this last group of patients, both biopsy modalities, Trucut and VABB, were utilized to biopsy breast nodule and microcalcification respectively, and both yielded ADH.

The median age of the patients was 51.7 years of age (table 1), and the ethnic distribution of patients is similar to and representative of our local multiracial population.

\section{(II) Radiological Characteristics}

Diagnostic mammograms of the 88 patients with ADH, including standard and magnification views, were retrieved and reviewed by at least three senior breast radiologists. Blinded to study outcomes, breast density was classified according to the American College of Radiology Breast Imaging Reporting and Data System (BI-RADS) system into four categories: almost entirely fat $(n=0)$, scattered fibroglandular tissue $(n=10)$, heterogeneously dense $(n=58)$, extremely dense $(n=22)$.

Fifty percent of patients $(n=45)$ underwent both mammogram and ultrasound screening modalities while the rest underwent mammogram screening only. Overall, $93 \%$ of mammographic lesions were classified radiographically as BIRADS category 4 . The most common abnormality noted on mammogram was microcalcifications in $91.1 \%(n=82)$, followed by the presence of a mass in $5.56 \%(n=5)$ and distortion in $3.33 \%(n=3)$. Microcalcification distribution was classified as diffuse, regional, clustered, linear or segmental. Diffuse calcification are scattered randomly throughout the breast. Regional distribution corresponds to calcifications scattered over a large volume ( $>2 \mathrm{cc}$ of breast tissue) without a ductal distribution. Clustered calcifications contain at least 5 microcalcifications in a small volume of tissue $(<1$ 
cc). Linear distribution describes calcifications arrayed in a line suggesting ductal extension. Segmental distribution refers to calcification in ducts and branches of a segment or lobe.

Of the lesions presenting as a mass, four had non-circumscribed margins; the margin details were obscured in one, microlobulated in one and spiculated in two patients. 36 out of 90 (40.0\%) did not have any residual lesion seen on mammography post core needle biopsy.

Forty-five patients (50\%) had an ultrasound evaluation, of which 23 had abnormal findings. Sonographically, most lesions appeared as a hypoechoic mass $(n=21)$ with oval $(n=11)$ or irregular shape $(n=10)$. The margins were indistinct $(n=9)$, circumscribed $(n=3)$, spiculated $(n=3)$, microlobulated $(n=4)$ or angular $(n=2)$. The mean diameter of the lesions measured at sonography was $10.5 \pm 7.3 \mathrm{~mm}$ (range, 3$45 \mathrm{~mm}$ ), $14.5 \mathrm{~mm}$ for malignant lesions and $9.3 \mathrm{~mm}$ for nonmalignant lesions $(p=0.545)$. The other 2 abnormal sonography revealed punctate calcifications.

Univariate analysis identified the following radiological features to be associated with an upgrade to malignancy (Tables 3 and 4): the presence of a mass on either ultrasound or mammogram ( $p=0.018$ and $p=0.026$ respectively), mammographic presence of microcalcifications $(p=0.047)$, diffuse microcalcification distribution on MMG $(p=0.034)$ and parenchymal density on MMG $(p=0.008)$. Mammographic parenchymal density $(p=0.0014)$ and presence of a mass on ultrasound $(p=0.010)$ remained significant on multivariate analysis.

\section{(III) Comparison of Biopsy Techniques}

Core needle samples were obtained using 11-gauge vacuum-assisted breast biopsy $(80 \%, n=72), 14$ gauge Trucut $(10 \%, n=9)$ or both $(10 \%, n=9)$. The median number of samples obtained were 12 (range 725 ) with the 11-gauge vacuum-assisted core needle biopsy and 6 (range 3-18) for the 14-gauge Trucut core biopsies. The subsequent upgrade rate of $A D H$ samples to malignancy was $26.0 \%$ (19 out of 72 ) for VAAB, $55.5 \%$ ( 5 out of 9 ) for Trucut and $22.2 \%$ ( 2 out of 9 ) for specimens taken by both VAAB and Trucut.

Univariate analysis revealed that use of Trucut biopsy method $(\mathrm{p}=0.031)$ was associated with upgrading. This correlated with the number of cores taken and was not significant on multivariate analysis.

\section{(IV) Histopathological Characteristics}

The architectural pattern of ADH seen on CNB specimens was cribriform in 56 cases (62.9\%), micropapillary in 33 cases (37.1\%) and solid in 1 case (1.1\%). The median number of ADH foci was 1 (mean $\pm \mathrm{SEM}, 1.24 \pm 0.26$ ), and the median size of $A D H$ foci was $1 \mathrm{~mm}$ (mean $\pm \mathrm{SEM}, 1.61 \pm 0.10 \mathrm{~mm}$ ). The extent of ADH was limited to 1 or 2 foci in 70 cases (77.7\%), confined to 3 foci in 11 cases $(12.2 \%)$, and involved 4 or more foci in 9 cases (9.9\%). The sensitivity and specificity of 3 or more foci of ADH seen on CNB in predicting upgrade on excision biopsy was 0.78 and 0.89 respectively, as opposed to 0.51 and 0.60 , respectively for less than 3 foci of lesion seen on CNB. 
Twenty-six of the $90 \mathrm{ADH}$ lesions (28.9\%) were subsequently upgraded to a breast malignancy on excision biopsy: 25 were DCIS (27.7\%) and 1 was invasive ductal carcinomas (1.1\%). Of the twenty-five DCIS lesions, 15 were cribriform, 9 were micropapillary and 1 was solid histologic type. The lesion that was upgraded to invasive carcinoma was mucinous carcinoma of nuclear grade 1 .

Amongst the remaining 64 lesions, excision biopsy revealed other forms of benign breast pathology in 35 lesions (38.5\%), such as fibrocystic change, apocrine metaplasia, sclerosing adenosis, usual ductal hyperplasia, fibroadenoma, intraductal papilloma and radial scar. Five (5.50\%) had coexisting atypical lobular hyperplasia (ALH). Only 24 lesions (26.4\%) remained as pure ADH. (Table 2).

On univariate analysis, histopathological factors associated with upgrading to malignancy included the number of tissue cores obtained $(p=0.045)$, number of separate foci of $A D H$ found on CNB $(p=0.024)$ and presence of microcalcification on CNB $(p=0.037)$.

On multivariate analysis, number of separate foci of $\mathrm{ADH}$ (Hazard ratio $=1.877,95 \% \mathrm{Cl} 1.831-1.920$, $\mathrm{p}=0.002$ ) remained significant for predicting upgrading of core biopsy diagnosed $A D H$ to malignancy.

\section{Low-risk definition}

The predicted probability of upgrade for each factor combination was estimated and the lowest risk categories (predicted probability of $5 \%$ or less) were identified. The definition of low risk for upgrade is therein defined as (1) two or less foci of ADH on biopsy, (2) mammographic density of scattered areas of fibroglandular density and (3) absence of mass on ultrasound. This represented $16 \%$ of the entire study set, which had an upgrade risk of $2.1 \%(95 \% \mathrm{Cl}: 1.1-3.4 \%)$. In contrast, the remainder of the sample not meeting this definition of low risk had an estimated upgrade rate of $29.0 \%$ (95\% Cl: $26.9 \%-34.2 \%)$. Based on the independent risk factors selected, we developed a nomogram using a multivariable logistic model to predict the probability of upgrading to in-situ or invasive carcinoma (Fig. 1). The sensitivity, specificity, positive predictive value, and negative predictive value of the nomogram in predicting upgrading were $91.9 \%, 79.0 \%, 80.1 \%$, and $92.9 \%$, respectively. Despite a lack of external validation sample available for this study, 10 -fold cross-validation analyses showed continued good performance with a cross-validation C-statistic of 0.81 .

\section{Discussion}

This is the first known study in Southeast Asia to incorporate radiological and histological characteristics to develop a predictive model for malignant upgrading of ADH diagnosed on core needle biopsy.

The upgrade rate in our study was $28.9 \%$, in the lower range of reported studies of 7 to $87 \%[1,2,15-20]$. This could be a result of improved breast imaging modalities, and a more stringent review of our screening mammograms by multiple dedicated breast radiologists. All lesions after biopsy are also discussed at a multidisciplinary meeting with radiologists, pathologists and surgeons. 
Our BSS participation rate increased from 10\% in 2005 to $39.6 \%$ in 2010. Performance indicators, with the except of recall rates, specificity, interval cancer rate (for first screen), generally improved over the years and are comparable with organized breast screening programmes in other developed countries [24, 25].

We found that the strongest factors predictive of upgrade to malignancy were presence of mass on sonography, mammographic parenchymal density and number of foci of ADH. Multivariate modelling was used to identify a subgroup of women with ADH on core biopsy who have low risk (2.1\%) of harboring concomitant malignancy, in whom surgical excision might be avoided. Approximately one eighth of our study population met the low-risk criteria, defined as (1) absence of mass on ultrasound, (2) mammographic parenchymal density of scattered areas of fibroglandular density, (3) two or less foci of ADH on core biopsy.

Similar to previous reports, our study also shows a higher upgrade rate in patients with higher mammographic parenchymal density [26]. Mammographic percent density, computed as the proportion of the parenchymal area occupied by radiologically dense breast tissue, has been related to screening sensitivity and specificity and is one of the strongest established risk factors for the development of DCIS [15] and invasive breast cancer [13]. Mammographic density is a function of genetic factors [2], is higher in nulliparous women, and is inversely associated with age and body mass index (BMI) $[13,16]$. Asian women have a lower average BMI compared to their western counterparts and more frequently have dense breasts on mammography [27-30]. The increased mammographic parenchymal density could account for the higher upgrading rates of CNB-diagnosed atypical ductal hyperplasia [31-35] as well as the younger peak age of breast cancer (10 years younger) $[36,37]$ seen in Asia compared to Western countries.

Microcalcification with or without a mass has been reported to be the most common finding on screening mammograms for both $\mathrm{ADH}(58 \%, 88 \%)$ and DCIS (68\%, 98\%) [38-40]. Ninety percent of non-palpable DCIS and $20 \%$ of non-palpable infiltrating carcinomas were identified by their microcalcifications [41]. The microcalcification morphology and distribution on imaging have been predictive of upgrading in several studies. In particular, calcifications which were clustered and had a segmental or linear branching distribution had a significantly higher association with malignancy. A subgroup with fine, rounded calcifications without density or mass has been identified as having a low risk of malignancy [42]. In our study, we demonstrated that patients with diffuse calcifications were more likely to have their core biopsy diagnosis upgraded on subsequent excision biopsy. Inherent in diffuse calcifications is the increased difficulty of taking an adequate representative sampling compared to clustered calcification. Hence, in patients with diffuse calcifications on their mammogram, it is recommended that sufficient and representative samples are taken for core biopsies to increase the adequacy of biopsy sampling. Likewise, for patients with ADH and diffuse calcifications, where the risk of false negative is higher, surgical excision needs to be considered if the adequacy of the sampling is of concern.

Although the breast screening programme is designed for women who are clinically asymptomatic, $12 \%$ $(11 / 90)$ of the screening mammograms revealed a mass, of which $64 \%(n=7)$ were clinically palpable. 
Out of the 11 mammograms harbouring a mass lesion, 5 lesions were upgraded to in situ or invasive carcinoma on excision biopsy. This underscores the importance of regular breast self-examination in addition to regular mammographic screening in detecting breast cancer in its early stages, similar to previous reports [43]. The vast majority of women diagnosed with ADH on CNB were however asymptomatic, with anomalous findings picked up only with mammographic screening. This highlights the complementary roles that breast self-examination and mammographic screening play. This is in contrast to the Canadian study that showed that annual mammography screening had no effect on breast cancer mortality beyond that of breast physical examinations [43]. This may be attributed to a difference in our culture and population screening habits, with a much to be improved percentage uptake of mammogram screening in Singapore.

Some studies have reported that the presence of a mass on imaging as a significant predictor of invasion $[44,45]$. The presence of a mass on imaging likely represents a more aggressive lesion with higher potential of local invasiveness: breaking through the basement membrane of the breast ducts and infiltration of adjacent tissues. In our study, the presence of a mass on either mammogram or ultrasound was associated with increased risk of upgrading to DCIS or invasive cancer, with presence of mass on ultrasound being an independent predictor of upgrade to in-situ or invasive malignancy. As ADH is a microscopic lesion, it is rare for pure $A D H$ to present as a mass, and therefore one should have a high suspicion of a false sampling, should a biopsy of a breast mass yield only ADH.

The histological criteria found to be independently associated with cancer upgrade in our study was the number of foci of ADH seen on core biopsy. Similar to previous studies [17, 18], our study also demonstrates that $\mathrm{ADH}$ involving 3 or more foci in CNB is an independent predictor of upgrading on excision, with upgrading found in $13(65.0 \%)$ out of 20 such cases, in contrast with 13 (18.6\%) out of 70 cases with $A D H$ confined to 1 or 2 foci. These findings suggest that $A D H$ confined to 1 or 2 foci in adequately sampled CNB specimens is predictive of a good outcome and that a greater number of foci of involvement strongly correlates with concomitant malignancy.

Some studies have purported that micropapillary histologic subtype predicted the presence of DCIS [17, $46,47]$. However, the architectural pattern of ADH relating to upgrading risk was not observed in our study $(p=0.80)$.

Although there is no universal agreement about the number of cores necessary to achieve an accurate histological diagnosis, most studies have demonstrated that increasing the number of core biopsies can decrease the risk of malignancy underestimation [38-41, 48]. Similarly, our study shows decreased upgrade rates with larger samples via larger needle gauge size and the use of vacuum device. However these did not reach significance on multivariate analysis. It is probable that this lack of independent correlation may be related to the size of the mammographic or pathologic lesion biopsied. One would also expect higher rates of underestimation when sampling is less adequate, which would be more likely in the case of larger target lesions. It also must be emphasized that, as shown also in the present study, 
even with use of vacuum assistance with an 11-gauge needle and complete removal of the mammographic lesion, there is still a $20 \%$ risk of malignant upgrade with the diagnosis of ADH.

Prior studies have investigated whether the absence of residual microcalcifications after biopsy would obviate the need for surgical excision and the consensus is mixed [18, 21, 49, 50]. In the study by Bonnett et al, residual calcifications were present in all cases showing carcinoma at open excision [20] . However, residual calcifications had low specificity because they were present in $71 \%$ of cases having negative surgical excisions. In our study, the presence of residual calcifications associated with ADH lesions is a strong predictor of upgrading on subsequent excision, with a sensitivity of 0.96 in our patient population. In the absence of residual calcifications post biopsy, $20 \%(n=7)$ of CNB-diagnosed ADH were still upgraded to in-situ or invasive cancer after surgical biopsy.

For women found to have a low risk of upgrade, short term radiologic follow up should be adequate to detect progression. This is supported by the fact that all but one of the upgraded lesions were in- situ disease. The only case upgraded to invasive carcinoma was a case of mucinous carcinoma for which CNB revealed a mucocele like lesion with $A D H$. Mucinous carcinoma usually carries a favourable prognosis with a low recurrence and metastatic rate. This was also demonstrated by Menen et al. [51] , where 125 women with low-risk ADH (using Nguyen et al.'s criteria [21]) were observed without surgical excision. With a median follow-up of 3 years (and chemoprevention use by $23 \%$ of women), only seven breast cancers occurred (5.6\%). Index site and ipsilateral cancer rates were comparable to the group that underwent excision while contralateral breast cancers only occurred in the surgical group.

Although there were predictive tools proposed before, they have been validated in different populations $[21,43]$. We have developed a predictive tool based on radiological and histological variables to predict risk of malignant upgrading in core needle biopsy diagnosed ADH in a multiracial heterogeneous Southeast Asian population, as shown in Figure 1. The variables included differ from the previous predictive tools and include histopathology in addition to imaging. Our results show that in patients whose risk score is less than or equal to -10 , there is a $2.1 \%$ or less chance of malignant upgrading. This is equivalent to the risk of a BIRADS 3 lesion which can be conservatively managed with short interval radiological surveillance. With further validation on a larger cohort, this nomogram has potential to be used as a adjunct to aid the surgeon and the patient to make an informed decision regarding open excision biopsy following a diagnosing of ADH on core needle biopsy.

In conclusion, we have retrospectively studied and examined the upgrade rate of core biopsy diagnosed $A D H$ on excision biopsy in Singaporean women. The strongest factors predictive of upgrade to malignancy were presence of mass on sonography, mammographic parenchymal density and the number of foci of ADH. We have also developed a nomogram, to help identify a group of women who are at low risk $(<5 \%)$ of upgrade to cancer, and may be candidates for avoiding open excision surgery, following a core-needle biopsy diagnosis of ADH.

\section{Declarations}


The authors received no specific funding for this work and have no conflicting interest or financial ties to disclose. The data that support the findings of this study are available on request from the corresponding author. The data are not publicly available due to their containing information that could compromise the privacy of research participants.

All procedures performed in studies involving human participants were in accordance with the ethical standards of the institutional and/or national research committee and with the 1964 Helsinki declaration and its later amendments or comparable ethical standards. Informed consent was obtained from all individual participants included in the study to use their data for research and publication.

\section{References}

1. Harvey JM, Sterrett GF, Frost FA (2002) Atypical ductal hyperplasia and atypia of uncertain significance in core biopsies from mammographically detected lesions: correlation with excision diagnosis. Pathology 34(5):410-416

2. Jackman RJ, Birdwell RL, Ikeda DM (2002) Atypical ductal hyperplasia: can some lesions be defined as probably benign after stereotactic 11-gauge vacuum-assisted biopsy, eliminating the recommendation for surgical excision? Radiology 224(2):548-554

3. Hartmann LC, Degnim AC, Santen RJ, Dupont WD, Ghosh K (2015) Atypical hyperplasia of the breast-risk assessment and management options. N Engl J Med 372(1):78-89

4. Page DL, Dupont WD, Rogers LW, Rados MS (1985) Atypical hyperplastic lesions of the female breast. A long-term follow-up study. Cancer 55(11):2698-2708

5. Dupont WD, Parl FF, Hartmann WH, Brinton LA, Winfield AC, Worrell JA, Schuyler PA, Plummer WD (1993) Breast cancer risk associated with proliferative breast disease and atypical hyperplasia. Cancer 71(4):1258-1265

6. Ma L, Boyd NF (1992) Atypical hyperplasia and breast cancer risk: a critique. Cancer causes control: $\operatorname{CCC} 3(6): 517-525$

7. Page DL, Jensen RA (1994) Evaluation and management of high risk and premalignant lesions of the breast. World journal of surgery 18(1):32-38

8. London SJ, Connolly JL, Schnitt SJ, Colditz GA (1992) A prospective study of benign breast disease and the risk of breast cancer. Jama 267(7):941-944

9. Page DL, Dupont WD (1993) Anatomic indicators (histologic and cytologic) of increased breast cancer risk. Breast Cancer Res Treat 28(2):157-166

10. Connolly JL, Schnitt SJ (1993) Clinical and histologic aspects of proliferative and non-proliferative benign breast disease. Journal of cellular biochemistry Supplement 17G:45-48

11. Marshall LM, Hunter DJ, Connolly JL, Schnitt SJ, Byrne C, London SJ, Colditz GA (1997) Risk of breast cancer associated with atypical hyperplasia of lobular and ductal types. Cancer epidemiology, biomarkers \& prevention: a publication of the American Association for Cancer Research. cosponsored by the American Society of Preventive Oncology 6(5):297-301 
12. Page DL, Rogers LW (1992) Combined histologic and cytologic criteria for the diagnosis of mammary atypical ductal hyperplasia. Human pathology 23(10):1095-1097

13. Tavassoli FA (1992) Intraduct hyperplasias, ordinary and atypical. In Pathology of the Breast Connecticut: Appleton and Lange:155-191

14. (R)) NCPGiONG (2018) Breast Cancer Screening and Diagnosis. National Comprehensive Cancer Network v3.2018:BSCR-8

15. Dahlstrom JE, Sutton S, Jain S (1996) Histological precision of stereotactic core biopsy in diagnosis of malignant and premalignant breast lesions. Histopathology 28(6):537-541

16. Liberman L, Cohen MA, Dershaw DD, Abramson AF, Hann LE, Rosen PP (1995) Atypical ductal hyperplasia diagnosed at stereotaxic core biopsy of breast lesions: an indication for surgical biopsy. AJR American journal of roentgenology 164(5):1111-1113

17. Ely KA, Carter BA, Jensen RA, Simpson JF, Page DL (2001) Core biopsy of the breast with atypical ductal hyperplasia: a probabilistic approach to reporting. Am J Surg Pathol 25(8):1017-1021

18. Sneige N, Lim SC, Whitman GJ, Krishnamurthy S, Sahin AA, Smith TL, Stelling CB (2003) Atypical ductal hyperplasia diagnosis by directional vacuum-assisted stereotactic biopsy of breast microcalcifications. Considerations for surgical excision. Am J Clin Pathol 119(2):248-253

19. Renshaw AA, Cartagena N, Schenkman RH, Derhagopian RP, Gould EW (2001) Atypical ductal hyperplasia in breast core needle biopsies. Correlation of size of the lesion, complete removal of the lesion, and the incidence of carcinoma in follow-up biopsies. Am J Clin Pathol 116(1):92-96

20. Bonnett M, Wallis T, Rossmann M, Pernick NL, Bouwman D, Carolin KA, Visscher D (2003) Histopathologic analysis of atypical lesions in image-guided core breast biopsies. Modern pathology: an official journal of the United States Canadian Academy of Pathology Inc 16(2):154160

21. Nguyen CV, Albarracin CT, Whitman GJ, Lopez A, Sneige N (2011) Atypical ductal hyperplasia in directional vacuum-assisted biopsy of breast microcalcifications: considerations for surgical excision. Ann Surg Oncol 18(3):752-761

22. Peña A, Shah SS, Fazzio RT, Hoskin TL, Brahmbhatt RD, Hieken TJ, Jakub JW, Boughey JC, Visscher DW, Degnim AC (2017) Multivariate model to identify women at low risk of cancer upgrade after a core needle biopsy diagnosis of atypical ductal hyperplasia. Breast Cancer Res Treat 164(2):295304

23. Peduzzi P, Concato J, Kemper E, Holford TR, Feinstein AR (1996) A simulation study of the number of events per variable in logistic regression analysis. J Clin Epidemiol 49(12):1373-1379

24. Morimoto T, Nagao T, Okazaki K, Kira M, Nakagawa Y, Tangoku A (2009) Current status of breast cancer screening in the world. Breast cancer 16(1):2-9

25. Robin A, Wilson (2006) European Group for Breast Cancer Screening: Breast Cancer Screening in Europe - current status. Eur J Cancer Suppl 4(2):4-5

26. Gill JK, Maskarinec G, Pagano I, Kolonel LN (2006) The association of mammographic density with ductal carcinoma in situ of the breast: the Multiethnic Cohort. Breast cancer research: BCR 8(3):R30 
27. Habel LA, Capra AM, Oestreicher N, Greendale GA, Cauley JA, Bromberger J, Crandall CJ, Gold EB, Modugno F, Salane M et al (2007) Mammographic density in a multiethnic cohort. Menopause 14(5):891-899

28. del Carmen MG, Hughes KS, Halpern E, Rafferty E, Kopans D, Parisky YR, Sardi A, Esserman L, Rust S, Michaelson J (2003) Racial differences in mammographic breast density. Cancer 98(3):590-596

29. El-Bastawissi AY, White E, Mandelson MT, Taplin S (2001) Variation in mammographic breast density by race. Ann Epidemiol 11(4):257-263

30. Tan SM, Evans AJ, Lam TP, Cheung KL (2007) How relevant is breast cancer screening in the Asia/Pacific. region? Breast 16(2):113-119

31. Bassett L, Poon C (2009) Frequency and Upgrade Rates of Atypical Ductal Hyperplasia Diagnosed at Stereotactic vacuum-assisted breast biopsy: 9-versus 11- Gauge. Breast Diseases: A Year Book Quarterly 20(4):388-389

32. Chae BJ, Lee A, Song BJ, Jung SS (2009) Predictive factors for breast cancer in patients diagnosed atypical ductal hyperplasia at core needle biopsy. World J Surg Oncol 7:77

33. McGhan LJ, Pockaj BA, Wasif N, Giurescu ME, McCullough AE, Gray RJ (2012) Atypical ductal hyperplasia on core biopsy: an automatic trigger for excisional biopsy? Ann Surg Oncol 19(10):3264-3269

34. Mooney KL, Bassett LW, Apple SK (2016) Upgrade rates of high-risk breast lesions diagnosed on core needle biopsy: a single-institution experience and literature review. Modern pathology: an official journal of the United States Canadian Academy of Pathology Inc 29(12):1471-1484

35. Winchester DJ, Bernstein JR, Jeske JM, Nicholson MH, Hahn EA, Goldschmidt RA, Watkin WG, Sener SF, Bilimoria MB, Barrera E, Jr. et al (2003) Upstaging of atypical ductal hyperplasia after vacuumassisted 11-gauge stereotactic core needle biopsy. Archives of surgery 138(6):619-622; discussion $622-613$

36. Pathy NB, Yip CH, Taib NA, Hartman M, Saxena N, lau P, Bulgiba AM, Lee SC, Lim SE, Wong JEL et al (2011) Breast cancer in a multi-ethnic Asian setting: Results from the Singapore-Malaysia hospitalbased breast cancer registry. The Breast 20:S75-S80

37. Kwong A, Mang OW, Wong CH, Chau WW, Law SC (2011) Breast cancer in Hong Kong, Southern China: the first population-based analysis of epidemiological characteristics, stage-specific, cancerspecific, and disease-free survival in breast cancer patients: 1997-2001. Ann Surg Oncol 18(11):3072-3078

38. Stomper PC, Cholewinski SP, Penetrante RB, Harlos JP, Tsangaris TN (1993) Atypical hyperplasia: frequency and mammographic and pathologic relationships in excisional biopsies guided with mammography and clinical examination. Radiology 189(3):667-671

39. Helvie MA, Hessler C, Frank TS, Ikeda DM (1991) Atypical hyperplasia of the breast: mammographic appearance and histologic correlation. Radiology 179(3):759-764

40. Dershaw DD, Abramson A, Kinne DW (1989) Ductal carcinoma in situ: mammographic findings and clinical implications. Radiology 170(2):411-415 
41. Feig SA: Mammographic evaluation of calcifications. In: Kopans DB, Mendelson EB, eds Syllabus: A Categorical Course in Breast Imaging Oak Brook: Radiological Society of North America Publications. edn.; 1995: 93-105

42. Boyd NF, Stone J, Martin LJ, Jong R, Fishell E, Yaffe M, Hammond G, Minkin S (2002) The association of breast mitogens with mammographic densities. British journal of cancer 87(8):876882

43. Miller AB, Wall C, Baines CJ, Sun P, To T, Narod SA (2014) Twenty five year follow-up for breast cancer incidence and mortality of the Canadian National Breast Screening Study: randomised screening trial. BMJ 348:g366

44. Schulz S, Sinn P, Golatta M, Rauch G, Junkermann H, Schuetz F, Sohn C, Heil J (2013) Prediction of underestimated invasiveness in patients with ductal carcinoma in situ of the breast on percutaneous biopsy as rationale for recommending concurrent sentinel lymph node biopsy. Breast 22(4):537-542

45. Park HS, Park S, Cho J, Park JM, Kim SI, Park BW (2013) Risk predictors of underestimation and the need for sentinel node biopsy in patients diagnosed with ductal carcinoma in situ by preoperative needle biopsy. Journal of surgical oncology 107(4):388-392

46. Yeh IT, Dimitrov D, Otto P, Miller AR, Kahlenberg MS, Cruz A (2003) Pathologic review of atypical hyperplasia identified by image-guided breast needle core biopsy. Correlation with excision specimen. Arch Pathol Lab Med 127(1):49-54

47. Wagoner MJ, Laronga C, Acs G (2009) Extent and histologic pattern of atypical ductal hyperplasia present on core needle biopsy specimens of the breast can predict ductal carcinoma in situ in subsequent excision. Am J Clin Pathol 131(1):112-121

48. Verkooijen HM (2007) Underestimation of malignancy of breast core-needle biopsy: concepts and precise overall and category-specifc estimates. Cancer 110(2):465-466; author reply 466

49. Arora S, Moezzi M, Kim U, Menes TS (2009) Is surgical excision necessary for atypical ductal hyperplasia diagnosed with 8 gauge stereotactic biopsy? The breast journal 15(6):673-674

50. Adrales G, Turk P, Wallace T, Bird R, Norton HJ, Greene F (2000) Is surgical excision necessary for atypical ductal hyperplasia of the breast diagnosed by Mammotome? American journal of surgery 180(4):313-315

51. Menen RS, Ganesan N, Bevers T, Ying J, Coyne R, Lane D, Albarracin C, Bedrosian I (2017) Long-Term Safety of Observation in Selected Women Following Core Biopsy Diagnosis of Atypical Ductal Hyperplasia. Ann Surg Oncol 24(1):70-76

\section{Tables}


Table 1

Demographic characteristics of the 88 patients diagnosed with ADH on core biopsy.

\begin{tabular}{|lll|}
\hline Characteristic & $\begin{array}{l}\text { Not upstaged } \\
\mathbf{N}=63, \mathbf{n}(\%)\end{array}$ & $\begin{array}{l}\text { Upstaged } \\
\mathbf{N}=\mathbf{2 5}, \mathbf{n}(\%)\end{array}$ \\
\hline Age at diagnosis & & \\
\hline Median \pm SD & $62.9 \pm 13.2$ & $61.3 \pm 15.7$ \\
\hline$<50$ & $25(40 \%)$ & $10(40 \%)$ \\
\hline$\geq 50$ & $38(60 \%)$ & $15(60 \%)$ \\
\hline Menopausal status & & \\
\hline Premenopausal & $36(57 \%)$ & $14(56 \%)$ \\
\hline Postmenopausal & $27(43 \%)$ & $11(44 \%)$ \\
\hline Race & & $18(72 \%)$ \\
\hline Chinese & $50(79 \%)$ & $4(16 \%)$ \\
\hline Malay & $6(9.5 \%)$ & $2(8.0 \%)$ \\
\hline Indian & $4(6.3 \%)$ & $1(4.0 \%)$ \\
\hline Other & $3(4.8 \%)$ & \\
\hline
\end{tabular}


Table 2

Summary of the histopathological diagnoses on excision biopsy.

\begin{tabular}{|ll|}
\hline Excision biopsy results & $\mathbf{n}(\%)$ \\
\hline Benign & $64(71.1)$ \\
\hline Non-proliferative lesions and proliferative lesions without atypia & $35(38.9)$ \\
\hline Fibrocystic change & $9(10.0)$ \\
\hline Apocrine metaplasia & $7(7.78)$ \\
\hline Sclerosing adenosis & $6(6.67)$ \\
\hline Usual ductal hyperplasia & $5(5.56)$ \\
\hline Intraductal papilloma & $4(4.44)$ \\
\hline Radial scar & $2(2.22)$ \\
\hline Fibroadenoma & $2(2.22)$ \\
\hline Atypical ductal hyperplasia & $24(26.7 \%)$ \\
\hline Atypical lobular hyperplasia & $5(5.55 \%)$ \\
\hline Malignant & $26(28.9 \%)$ \\
\hline Ductal carcinoma in-situ & $25(27.8 \%)$ \\
\hline Invasive carcinoma & $1(1.11 \%)$ \\
\hline
\end{tabular}


Table 3

Univariate analysis of the radiological factors predicting for upgrade to DCIS or invasive carcinoma on excision biopsy.

\begin{tabular}{|c|c|c|c|c|}
\hline \multirow[t]{2}{*}{ Variable } & \multicolumn{2}{|c|}{$\begin{array}{l}\text { Upgrade to DCIS or IBC } \\
\text { (total } \mathrm{N}=90 \text { lesions); } \mathrm{n} \\
(\%)\end{array}$} & \multirow[t]{2}{*}{$\begin{array}{l}\text { Odds Ratio } \\
(95 \% \mathrm{Cl})\end{array}$} & \multirow[t]{2}{*}{ p-value } \\
\hline & No $(n=64)$ & Yes $(n=26)$ & & \\
\hline \multicolumn{5}{|l|}{ Imaging findings } \\
\hline $\begin{array}{l}\text { Imaging modality } \\
\text { Mammogram alone } \\
\text { Mammogram + US }\end{array}$ & $\begin{array}{l}35(54.7) \\
29(45.3)\end{array}$ & $\begin{array}{l}10(38.5) \\
16(61.5)\end{array}$ & $1.80(0.81-4.58)$ & 0.224 \\
\hline Mass present on US & $7(10.9)$ & $14(51.9)$ & $\begin{array}{l}5.81(1.33- \\
25.32)\end{array}$ & $0.018^{*}$ \\
\hline Mass lesion on MMG & $1(1.6)$ & $4(14.8)$ & $4.96(1.68-8.76)$ & $0.026^{*}$ \\
\hline Residual lesion post-CNB on MMG & $20(31.3)$ & $34(54.8)$ & $2.35(0.87-6.37)$ & 0.092 \\
\hline Microcalcification present, & $61(95.3)$ & $21(80.8)$ & $2.23(1.23-3.67)$ & $0.047^{\star}$ \\
\hline $\begin{array}{l}\text { Microcalcification } \\
\text { Morphology } \\
\text { None } \\
\text { Amorphous } \\
\text { Coarse heterogenous } \\
\text { Fine pleiomorphic } \\
\text { Linear } \\
\text { Distribution } \\
\text { None } \\
\text { Diffuse } \\
\text { Regional } \\
\text { Grouped } \\
\text { Segmental }\end{array}$ & $\begin{array}{l}3(4.7) \\
19(29.7) \\
26(40.6) \\
11(17.2) \\
5(7.8) \\
3(4.7) \\
2(3.1) \\
9(14.1) \\
34(53.1) \\
16(25.0)\end{array}$ & $\begin{array}{l}5(19.2) \\
4(15.4) \\
11(42.3) \\
4(15.1) \\
2(7.7) \\
5(19.2) \\
3(11.5) \\
1(3.9) \\
10(38.5) \\
7(26.9)\end{array}$ & $0.55(0.37-1.23)$ & 0.078 \\
\hline $\begin{array}{l}\text { Breast composition } \\
\text { Extremely dense } \\
\text { Heterogenously dense } \\
\text { Scattered areas of fibroglandular } \\
\text { density }\end{array}$ & $\begin{array}{l}20(31.3) \\
40(62.5) \\
4(6.3)\end{array}$ & $\begin{array}{l}2(7.7) \\
18(69.2) \\
6(23.1)\end{array}$ & $\begin{array}{l}0.31(0.07-1.24) \\
0.08(0.10-0.46)\end{array}$ & $0.008^{*}$ \\
\hline
\end{tabular}


Table 4

Univariate analysis of histological factors predicting for upgrade to DCIS or invasive carcinoma on excision biopsy.

\begin{tabular}{|c|c|c|c|c|}
\hline \multirow[t]{2}{*}{ Variable } & \multicolumn{2}{|c|}{$\begin{array}{l}\text { Upgrade to DCIS or } \\
\text { IBC } \\
\text { (total } \mathrm{N}=90 \\
\text { lesions); } \mathrm{n}(\%)\end{array}$} & \multirow[t]{2}{*}{$\begin{array}{l}\text { Odds Ratio } \\
(95 \% \mathrm{Cl})\end{array}$} & \multirow[t]{2}{*}{$\begin{array}{l}\mathrm{p}- \\
\text { value }\end{array}$} \\
\hline & $\begin{array}{l}\text { No }(n= \\
64)\end{array}$ & $\begin{array}{l}\text { Yes }(n= \\
26)\end{array}$ & & \\
\hline \multicolumn{5}{|l|}{ Pathological variables } \\
\hline $\begin{array}{l}\text { CNB technique, } n(\%) \\
\text { Trucut } \\
\text { Trucut and VABB } \\
\text { VABB }\end{array}$ & $\begin{array}{l}4(6.25) \\
7(10.9) \\
53 \\
(82.8)\end{array}$ & $\begin{array}{l}5(19.2) \\
2(7.7) \\
19 \\
(73.1)\end{array}$ & $\begin{array}{l}0.56(0.11- \\
0.95) \\
0.31(0.09- \\
0.87)\end{array}$ & $0.031 *$ \\
\hline $\begin{array}{l}\text { No. of tissue cores obtained, median (interquartile } \\
\text { range) }\end{array}$ & $\begin{array}{l}5(1- \\
17)\end{array}$ & $\begin{array}{l}5(1- \\
10)\end{array}$ & $\begin{array}{l}0.89(0.80- \\
0.94)\end{array}$ & $0.045^{\star}$ \\
\hline $\begin{array}{l}\text { No. of separate foci of ADH found on CNB, median } \\
\text { (interquartile range) }\end{array}$ & $1(1-5)$ & $2(1-6)$ & $\begin{array}{l}1.52(1.08- \\
1.98)\end{array}$ & $0.024 *$ \\
\hline Presence of microcalcification in biopsy & 37 & 12 & $\begin{array}{l}1.34(1.03- \\
1.65)\end{array}$ & $0.037 *$ \\
\hline $\begin{array}{l}\text { ADH architectural pattern } \\
\text { Cribriform } \\
\text { Micropapillary } \\
\text { Tufting } \\
\text { Solid }\end{array}$ & $\begin{array}{l}37 \\
22 \\
5 \\
0\end{array}$ & $\begin{array}{l}19 \\
4 \\
2 \\
1\end{array}$ & $\begin{array}{l}1.23(0.80- \\
1.72)\end{array}$ & 0.80 \\
\hline
\end{tabular}


Table 5

Multivariate analysis of factors predicting for upgrade to DCIS or invasive carcinoma on excision biopsy.

\begin{tabular}{|llll|}
\hline \multirow{2}{*}{ Variable } & \multicolumn{2}{l|}{ Multivariate analysis } \\
\cline { 2 - 4 } & Hazard ratio & $\mathbf{9 5 \%} \mathbf{C l}$ & $\mathbf{p}$ \\
\hline Mammographic density & & & 0.014 \\
$\begin{array}{l}\text { - Heterogeneously dense } \\
\text { - Scattered areas of fibroglandular density }\end{array}$ & 0.32 & $0.010-0.89$ & \\
\hline Presence of mass on ultrasound & 10.50 & $9.005-0.35$ & \\
\hline No. of foci of ADH & 1.877 & $1.831-1.920$ & 0.002 \\
\hline
\end{tabular}

\section{Figures}

Points (per variable)

Mammographic density

Presence of mass on ultrasound

No. of foci of $A D H$

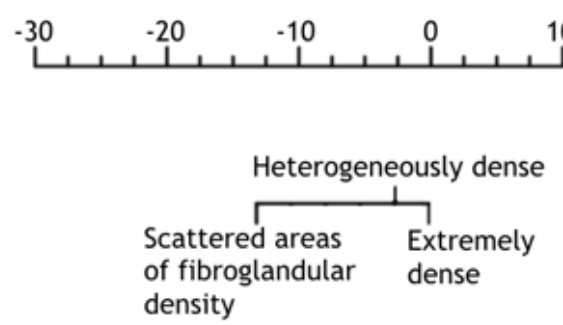

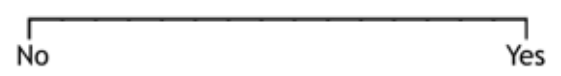

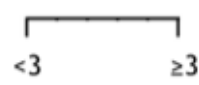

Total Points

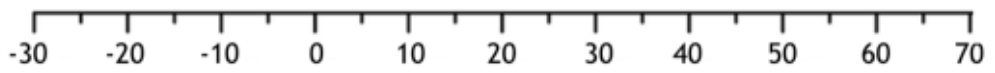

Risk of upstaging to in-situ or invasive carcinoma

\begin{tabular}{ccccccccc}
\hline 0.01 & 0.05 & 0.1 & 0.2 & 0.3 & 0.4 & 0.5 & 0.6
\end{tabular}

\section{Figure 1}

Nomogram predicting risk of upstaging to in-situ or invasive carcinoma for core needle biopsy diagnosed $\mathrm{ADH}$. 